\title{
CARBON EMISSION PREDICTION MODEL OF AGROFORESTRY ECOSYSTEM BASED ON SUPPORT VECTOR REGRESSION MACHINE
}

\author{
CAI, J. - MA, X. \\ College of Economics and Management, Anhui Agricultural University, Hefei 230036, China \\ *Corresponding author \\ e-mail:maxiaoqian4568@163.com \\ (Received 29 $9^{\text {th }}$ Dec 2018 ; accepted $8^{\text {th }}$ Mar 2019)
}

\begin{abstract}
The carbon emission prediction model of agroforestry ecosystem based on least squares regression method has no learning process for data samples, it is difficult to accurately describe the nonlinear relationship among them, and the prediction accuracy is poor. A carbon emission prediction model of agroforestry ecosystem based on support vector regression was designed. Seven carbon sources, including root decomposition, chemical fertilizer, pesticide, agricultural film, agricultural irrigation, agricultural machinery and farmland tillage, were selected as influencing factors of carbon emissions in agroforestry ecosystem. The SVR model for carbon emissions prediction in agroforestry ecosystem was constructed, and the regression function of sample data was solved by optimizing the training sample data based on the basic principle of support vector regression machine. On this basis, the data of influencing factors of agroforestry ecosystem were normalized and substituted into the model to predict the carbon emission results of agroforestry ecosystem system. Experiments show that the errors of the designed model in predicting the average carbon emissions of agroforestry ecosystems in the two experimental provinces from 2010 to 2017 are $5.9 / 10^{4} \mathrm{t}$ and $6.4 / 10^{4} \mathrm{t}$, respectively, which are lower than those of other models. The average time of predicting the carbon emissions of agroforestry ecosystems in the two experimental provinces from 2006 to 2015 is about 4.15 s, which shows that the model can predict agriculture. The results of forest ecosystem carbon emissions have the advantages of high efficiency, high precision and comprehensiveness.
\end{abstract}

Keywords: support vector regression machine, agroforestry ecosystem, carbon emission, prediction, model, regression function

\section{Introduction}

Since the late nineteenth century, the global surface temperature has risen by $0.4-$ $0.8^{\circ} \mathrm{C}$. Global warming, an environmental change problem, has attracted widespread attention in the international community. Greenhouse gas emissions are the main causes of climate warming (Grinblat et al., 2015). The main greenhouse gases produced by human activities are carbon dioxide, methane, nitrous oxide and fluoride, among which carbon dioxide is the most important anthropogenic greenhouse gas (Babaranti, 2019). Fluoride itself does not contain Greenhouse Effect, but a greenhouse gas. The IPCC Fourth Assessment Report pointed out that the increase of global carbon dioxide concentration was mainly attributed to the use of fossil fuels (Onwuka et al., 2019). The increase of nitrogen monoxide concentration was mainly attributed to the use of agriculture and fossil fuels. The increase of nitrogen monoxide concentration was mainly attributed to the agroforestry ecosystem (Zhang et al., 2016). With the progress and extension of agroforestry ecological science and technology, the industrialization trend of agroforestry ecosystem has been strengthened. For example, the United States is a typical modern country of agroforestry ecosystem. Its development of agroforestry ecosystem is essentially based on technology and energy. The degree of mechanization 
and chemistry of agroforestry ecological production is quite high, and its income and input of agroforestry ecological energy is as high as $1: 15$, which is the most in the world. Facing the increasingly serious contradiction between land and population, China with a large population is also vigorously promoting the development of modern agroforestry ecology. It can be seen that the agroforestry and ecological production sector has become an important area of fossil energy consumption. In 2014, the share of agricultural greenhouse gas emissions calculated by carbon dioxide equivalent accounted for $13.5 \%$ of total greenhouse gas emissions. It can be seen that agroforestry ecosystem has become one of the main sources of greenhouse gas emissions (Ouyang et al., 2019).

Scholars in China and abroad have shown that the broad definition of agroforestry ecosystem refers to the five industrial forms of planting, forestry, animal husbandry, fisheries and sideline (Franzluebbers et al., 2016). Carbon emissions from agroforestry ecosystems mainly come from the following aspects: (1) The use of chemical fertilizers will produce greenhouse gas emissions such as nitrous oxide, methane and so on. At the same time, the production and transportation of chemical fertilizers will produce carbon emissions. (2) The use of pesticides, including their carbon emissions during production and transportation. (3) The use of agricultural film products, including carbon emissions in the production process. (4) Carbon emissions from fossil fuels directly consumed, including the use of agricultural machinery and irrigation equipment. (5) Loss of soil organic carbon during farming. (6) Combustion of crop straw (Khanchoul et al., 2019).

Agroforestry ecosystem is a special ecosystem: it is not only a carbon source manufacturing system, but also a carbon sink absorption system (Vignola et al., 2015). Carbon sources in agroforestry ecosystems mainly come from planting and aquaculture, which are closely related to human beings. Carbon sinks mainly come from forestland and agricultural land (Anderegg et al., 2015). In recent years, the world's agroforestry ecosystem has entered the era of low-carbon economy, while the development of lowcarbon agroforestry ecosystem in China is still in its infancy, and low-carbon agroforestry ecosystem is an important issue facing our country at present. In this context, the study of carbon emissions from agroforestry ecosystems in China has a certain practical significance (Oyedotun et al., 2019).

At present, there are many ways to predict carbon emissions in agroforestry ecosystems. Because there are some technical and practical difficulties in observing and counting carbon emissions flux, the existing methods are based on some easy statistical data. Wall et al. (2015) predicted carbon emissions from agroforestry ecosystems through tillage data and meteorological information. Brogniez et al. (2015) predicted carbon emissions from agroforestry ecosystems according to the fertilization on farmland. Maas et al. (2015) predicted carbon emissions from agroforestry ecosystems by testing soil organic carbon content (Roslee, 2019). The least squares regression method and ridge regression method are mostly used in the above-mentioned carbon emission models of agroforestry ecosystems. They have the problems of weak stability and explanability, and are difficult to determine parameters. At the same time, the forecasting model has no learning process for data samples, and it is difficult to accurately describe the non-linear relationship among them, so the forecasting accuracy is poor. Now the mainstream carbon emission prediction method is based on the carbon emissions of fossil energy. The main carbon emissions of agroforestry ecosystem are mainly caused by the use of agricultural, chemical fertilizer, agricultural film and diesel 
oil, so the carbon emissions are predicted from the perspective of input (Sharma et al., 2019).

Support Vector Machine (SVM) is a new machine learning algorithm based on statistical learning theory. Because of its excellent learning performance, it has been successfully applied in many fields such as face recognition, handwritten numeral recognition and image retrieval, which can be used for classification and regression problems. In order to solve the defects existing in the prior method, an effective carbon emission prediction method is found, and the basis for the implementation of the highefficiency energy-saving emission reduction decision is provided. In this paper, a prediction model of carbon emissions in agroforestry ecosystem based on SVM is designed, which provides an important basis for making efficient energy-saving and emission reduction decisions (Khanchoul et al., 2019).

\section{Materials and methods}

\section{Selection of influencing factors of carbon emission in agroforestry ecosystem}

When the carbon source of the ecosystem was predicted, the carbon emissions of the selected two experimental provinces increased at a constant rate. GDP is the final result of the production activities of all permanent units in a country (or region) calculated by market price. and obtaining the GDP data according to the GDP accounting system. There are seven kinds of carbon sources for predicting carbon emissions in agroforestry ecosystems (Sinare and Gordon, 2015): first, the carbon emissions caused by the use of chemical fertilizers; second, the carbon emissions caused by the use of pesticides; third, the carbon emissions caused by the decomposition of residual roots after harvesting crops; fourth, the carbon emissions from indirect consumption of fossil fuels during irrigation; fifth, carbon emissions caused by the use of agricultural film; Sixth, the destruction of soil organic carbon pools by farmland tillage, resulting in the loss of a large amount of organic carbon into the air and carbon emissions; seventh, the direct or indirect consumption of fossil fuels (diesel, electricity, etc.) by agricultural machinery (Michael et al., 2015). These seven carbon sources were selected as independent variables of carbon emission prediction in the studied agroforestry ecosystem.

Figure 1 depicts the proportion of different carbon sources in total carbon emissions in the agroforestry ecosystem of China. It can be concluded that the carbon emissions of agroforestry ecosystem in this province are mainly caused by root decomposition after harvesting (accounting for 59.8712\% of the carbon emissions of agroforestry ecosystem). In agroforestry ecosystem, the proportion of carbon emissions of various types in total emissions is in the order of root decomposition $(59.8712 \%)$, chemical fertilizer $(28.0495 \%)$, pesticide $(4.9972 \%)$, agricultural film $(3.0612 \%)$, agricultural irrigation $(2.2927 \%)$, agricultural machinery $(1.7519 \%)$ and farmland tillage $(0.0123 \%)$. The proportion of root decomposition in agricultural carbon emissions is prominent due to the large agricultural planting area and unscientific farmland management in the province (Carsan et al., 2015).

\section{SVR model for prediction of carbon emissions in agroforestry ecosystem}

The SVR model for carbon emission prediction of agroforestry ecosystem was established. The results of carbon emission of agroforestry ecosystem were predicted 
based on the above seven factors: root decomposition, chemical fertilizer, pesticide, agricultural film, agricultural irrigation, agricultural machinery and farmland tillage.

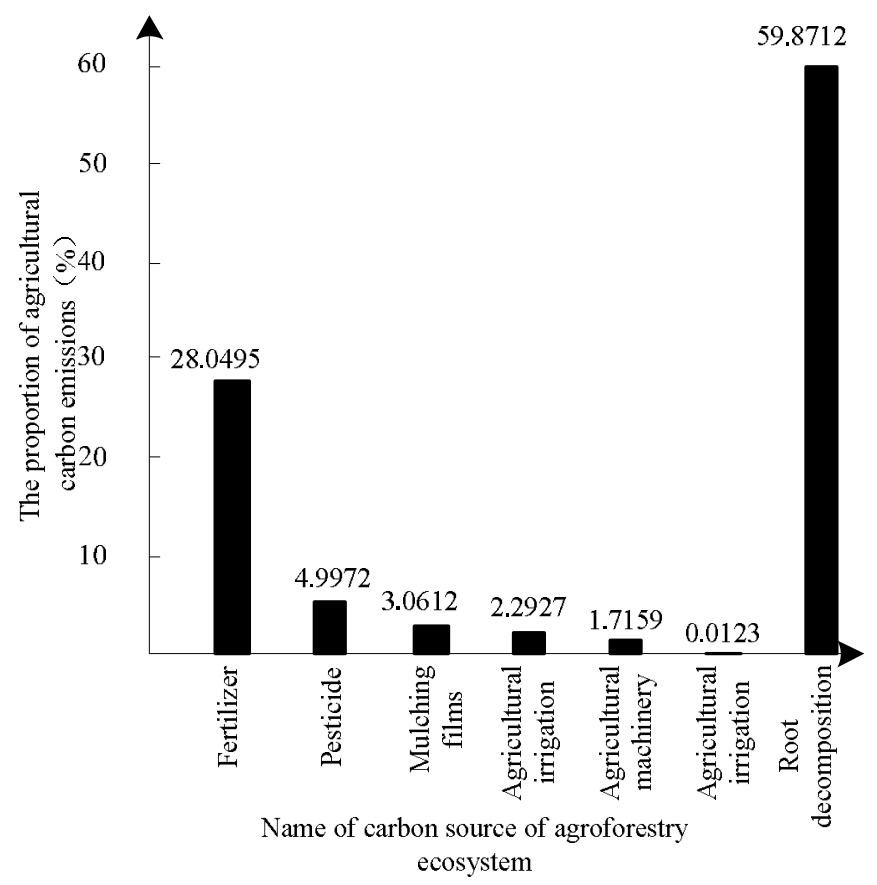

Figure 1. Emission ratio of agroforestry ecosystem in a province

\section{Basic principle of support vector regression machine}

SVR is a machine learning method based on statistical learning theory (Sloat et al., 2015). Because it is especially suitable for limited samples, it can obtain global optimum theoretically and has a good generalization ability. Moreover, its computational complexity is independent of the dimension of samples. It has been well applied in function approximation and regression estimation (Helen, 2016). Given the training set $T=\left\{\left(x_{1}, y_{1}\right), \cdots,\left(x_{n}, y_{n}\right)\right\}, x_{i} \in R^{m}, y_{i} \in R, i=1, \cdots, n$, where $x_{i}$ and $y_{i}$ represent the input factor and the expected value, respectively, and $n$ is the total number of data points. If we can deduce the $y$ value of any model $x$ by a linear function $y=f(x)=(w \bullet x)+b$ on $R^{m}$, it is called linear regression problem. The linear regression problem can be converted to the following optimization problem (Rueda et al., 2015):

$$
\left\{\begin{aligned}
\min & \frac{1}{2}\|w\|^{2}+C \frac{1}{n} \sum_{i=1}^{n}\left(\xi_{i}+\xi_{i}^{*}\right), \\
\text { s.t. } & \left(\left(w \bullet x_{i}\right)+b\right)-y_{i} \leq \varepsilon+\xi_{i}, \\
& i=1,2, \cdots, n \\
& y_{i}-\left(\left(w \bullet x_{i}\right)+b\right) \leq \varepsilon+\xi_{i}^{*}, \\
& i=1,2, \cdots, n \\
& \xi_{i}, \xi_{i}^{*} \geq 0, i=1,2, \cdots, n
\end{aligned}\right.
$$


In the formula, $C$ is the penalty parameter, $\xi_{i}$ and $\xi_{i}^{*}$ are the relaxation variables, $\varepsilon$ is the threshold of insensitive loss function, which is used for fitting accuracy (He and Rong, 2015). $\|w\|^{2}$ is the confidence risk; $b$ is the parameter to be identified.

Generally, the dual problem of model (Eq.l) is introduced instead of solving model directly.

$$
\left\{\begin{array}{l}
\min \frac{1}{2} \sum_{i, j=1}^{n}\left(\alpha_{i}^{*}-\alpha_{i}\right)\left(\alpha_{j}^{*}-\alpha_{j}\right)\left(x_{i}-x_{j}\right)+ \\
\varepsilon \sum_{i=1}^{n}\left(\alpha_{i}^{*}+\alpha_{i}\right)-\sum_{i=1}^{n} y_{i}\left(\alpha_{i}^{*}-\alpha_{i}\right), \\
\text { s.t. } \quad \sum_{i=1}^{n}\left(\alpha_{i}-\alpha_{i}^{*}\right)=0, \\
\quad 0 \leq \alpha_{i}, \alpha_{i}^{*} \leq \frac{C}{n}, i=1,2, \cdots, n
\end{array}\right.
$$

In the formula, $\alpha_{i}$ and $\alpha_{i}^{*}$ are the support vector parameters.

If $\bar{\alpha}_{i} \neq 0$ or $\bar{\alpha}_{i}^{*} \neq 0$ is the optimal solution, the input $x_{i}$ in the training set is called support vector. The correlation coefficients of regression function are: $S_{1}=\left\{i \mid \bar{\alpha}_{i} \in(0, C / n)\right\}, S_{2}=\left\{i \mid \bar{\alpha}_{i}^{*} \in(0, C / n)\right\}$, find $j \in S_{1}$ or $k \in S_{2}$, and it can be calculated:

$$
\bar{b}=y_{i}-\sum_{i=1}^{n}\left(\bar{\alpha}_{i}^{*}-\bar{\alpha}_{i}\right)\left(x_{i} \bullet x_{j}\right)+\varepsilon
$$

or

$$
\bar{b}=y_{k}-\sum_{i=1}^{n}\left(\bar{\alpha}_{i}^{*}-\bar{\alpha}_{i}\right)\left(x_{i} \bullet x_{k}\right)-\varepsilon
$$

Finally, the linear regression function of the training sample is obtained as follows:

$$
f(x)=\sum_{i=1}^{n}\left(\bar{\alpha}_{i}^{*}-\bar{\alpha}_{i}\right)\left(x_{i} \bullet x\right)+\bar{b}
$$

It is not difficult to see that the dual problem (Eq.2) and regression function (Eq.5) only involve the inner product operation $\left(x_{i} \bullet x_{j}\right)$ between sample inputs. Therefore, the inner product kernel function $K\left(x_{i}, x_{j}\right)$ can be introduced to transform the linear regression problem into the non-linear regression problem in the high dimensional space (Hilbert space) (Dressler et al., 2015). The support vector regression model ( $\varepsilon$-SVR) can be constructed (Marilice et al., 2015).

$$
\begin{cases}\min & \frac{1}{2} \sum_{i, j=1}^{n}\left(\alpha_{i}^{*}-\alpha_{i}\right)\left(\alpha_{j}^{*}-\alpha_{j}\right) K\left(x_{i}, x_{j}\right)+ \\ \varepsilon \sum_{i=1}^{n}\left(\alpha_{i}^{*}+\alpha_{i}\right)-\sum_{i=1}^{n} y_{i}\left(\alpha_{i}^{*}-\alpha_{i}\right), \\ \text { s.t. } \quad \sum_{i=1}^{n}\left(\bar{\alpha}_{i}-\bar{\alpha}_{i}^{*}\right)=0, \\ \quad 0 \leq \alpha_{i}, \alpha_{i}^{*} \leq \frac{C}{n}, i=1,2, \cdots, n\end{cases}
$$


When the optimal solution $\bar{\alpha}=\left(\bar{\alpha}_{1}, \bar{\alpha}_{1}^{*}, \cdots, \bar{\alpha}_{n}, \bar{\alpha}_{n}^{*}\right)^{T}$ is obtained, the corresponding training sample regression function becomes as follows:

$$
f(x)=\sum_{i=1}^{n}\left(\bar{\alpha}_{i}^{*}-\bar{\alpha}_{i}\right) K\left(x_{i}, x\right)+\bar{b}
$$

Choose $\bar{\alpha}_{j}$ or $\bar{\alpha}_{k}^{*}$ in $\left(0, \frac{C}{n}\right)$, and the corresponding $\bar{b}$ is:

$$
\bar{b}=y_{j}-\sum_{i=1}^{n}\left(\bar{\alpha}_{i}^{*}-\bar{\alpha}_{i}\right) K\left(x_{i}, x_{j}\right)+\varepsilon
$$

or

$$
\bar{b}=y_{k}-\sum_{i=1}^{n}\left(\bar{\alpha}_{i}^{*}-\bar{\alpha}_{i}\right) K\left(x_{i}, x_{k}\right)-\varepsilon
$$

\section{Establishment of SVR carbon emission prediction model}

A multi-input and single-output support vector regression model is constructed by constructing the relationship between the input and the output through the SVR model, as shown in Figure 2 (Benjamin et al., 2018). The specific steps are as follows:

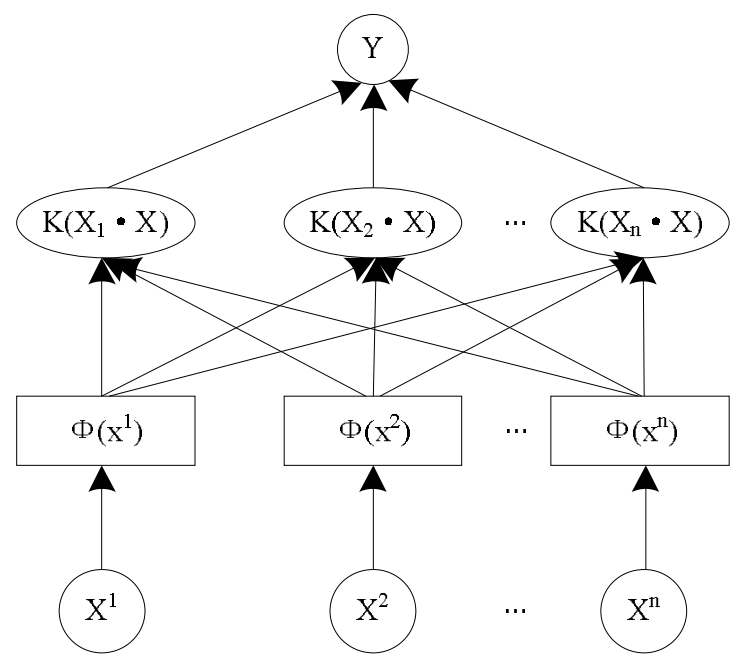

Figure 2. Support vector regression machine model

In Figure 2, carbon emissions and their influencing factors are input, and carbon emission values are outputted. The first step is to classify the samples (Ping et al., 2015). Taking an agroforestry ecosystem in a province of China as an example, the data of carbon emissions and their influencing factors from 1990 to 2010 and 2011 to 2017 were taken as training samples and testing samples respectively. The influencing factors were root decomposition, chemical fertilizer, pesticide, agricultural film, agricultural irrigation, agricultural machinery and farmland tillage (carbon emissions and their shadows due to space limitation). Sound factor data sheet is not described in detail. 
The second step is to normalize all sample data, that is, to normalize the independent variables and dependent variables in all samples with the following formula, so that all data are in $[0,1]$ (Terrado et al., 2015).

$$
\begin{gathered}
x_{i l}=\frac{x_{i l}^{0}-\min x_{i l}^{0}}{\max x_{i l}^{0}-\min x_{i l}^{0}}, i=1,2, L, n, l=1,2, L, 7 \\
y_{i}=\frac{i_{i}^{0}-\min y_{i}^{0}}{\max y_{i}^{0}-\min y_{i}^{0}}, i=1,2, L, n
\end{gathered}
$$

The third step is to select the best penalty coefficients $C$ and $\gamma$ of training samples and test samples. Firstly, the parameters $C$ and $\gamma$ are selected roughly, and the range of their values are $l b C \in[-10,10], l b \gamma \in[-10,10]$, which are substituted into the model to get the rough map. According to the printed rough map, the range of parameters are $l b C \in[-8,8], l b \gamma \in[-10,10]$, and then substituted into the SVR carbon emission prediction model to get the fine map. The grid width $m$, cross validation fold $k$ and regression bandwidth $\varepsilon$ remain unchanged, which are 1, 5 and 0.05 , respectively. The optimum values $C^{*}$ and $\gamma^{*}$ of $C$ and $\gamma$ are 9.18959 and 0.0358968 , respectively.

The fourth step is to construct and test the SVR carbon emission prediction model. The SVR carbon emission prediction model was constructed by using the above optimal parameters $C^{*}, \gamma^{*}$ and all training samples. The regression function was obtained as follows:

$$
\begin{aligned}
f(x) & =2.5460 K\left(x_{2}, x\right)+1.3375 K\left(x_{3}, x\right)-9.1896 K\left(x_{4}, x\right) \\
& +4.9274 K\left(x_{5}, x\right)+9.1896 K\left(x_{6}, x\right)-9.1896 K\left(x_{7}, x\right) \\
& -7.3493 K\left(x_{10}, x\right)+5.0624 K\left(x_{12}, x\right)-9.1896 K\left(x_{13}, x\right) \\
& -9.1896 K\left(x_{14}, x\right)-9.1896 K\left(x_{15}, x\right)+9.1896 K\left(x_{16}, x\right) \\
& +9.1896 K\left(x_{17}, x\right)-0.4126 K\left(x_{19}, x\right)+1.7260 K\left(x_{21}, x\right) \\
& +9.1896 K\left(x_{22}, x\right)-1.7442 K\left(x_{24}, x\right)+0.9176
\end{aligned}
$$

$x$ is the input sample whose model parameters are not zero, that is, support vector; $f(x)$ is the set of output vectors. After the regression function $f(x)$ is obtained, the correlation coefficients of training samples and test samples are substituted into $f(x)$ to get $S_{1}=0.997601$ and $S_{2}=0.976871$, respectively. At the same time, the training sample and the test sample are substituted into the model to obtain the comparison chart between the original data and the fitting data, as shown in Figure 3. Therefore, the regression function $f(x)$ can be used as a carbon emission prediction model of agroforestry ecological coefficient in a province of China.

\section{Results}

\section{Accuracy analysis of model prediction results}

In order to verify the accuracy of the carbon emission prediction model of agroforestry ecosystem based on vector regression machine, two provinces in China are 
represented by experimental object 1 and experimental object 2 . The carbon emissions of agricultural and forestry ecosystems in 2010-2017 in two experimental provinces were predicted by using this model, the carbon emission prediction model of agricultural and fore ecosystems based on tillage data and meteorological information, the carbon emission prediction model of agricultural and forestry ecosystems based on least square regression method and the carbon emission prediction model of agricultural and forestry ecosystems based on ridge regression method, respectively. The results are shown in Tables 1 and 2.

In order to reflect the predicted results of different models more clearly, the data in Tables 1 and 2 are described in the form of polyline graphs, and the results are shown in Figures 4 and 5.

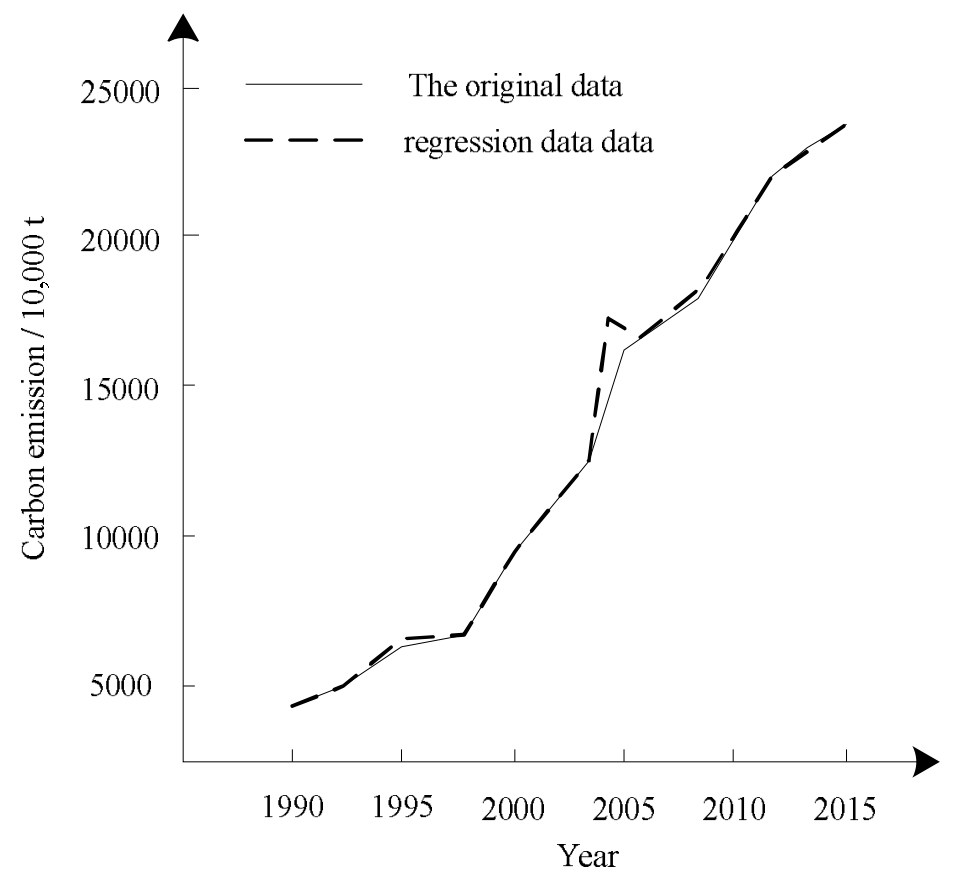

Figure 3. Comparison of original data and regression data

Table 1. Prediction of carbon emissions from agroforestry ecosystem in Provinces 1, 20102017

\begin{tabular}{c|c|c|c|c|c}
\hline $\begin{array}{c}\text { Particular } \\
\text { year }\end{array}$ & $\begin{array}{c}\text { Actual } \\
\text { emissions /10 }\end{array}$ & $\begin{array}{c}\mathbf{4} \mathbf{t} \\
\text { Paper } \\
\text { model /10 } \mathbf{4} t\end{array}$ & $\begin{array}{c}\text { Prediction model } \\
\text { based on tillage data } \\
\text { and meteorological } \\
\text { information /10 } \mathbf{t}\end{array}$ & $\begin{array}{c}\text { Prediction } \\
\text { model based on } \\
\text { least square } \\
\text { regression /10 } \mathbf{t}\end{array}$ & $\begin{array}{c}\text { Forecasting } \\
\text { model based on } \\
\text { ridge regression } \\
\text { method /10 } \mathbf{t}\end{array}$ \\
\hline 2010 & 7033.5 & 7046.0 & 7139.4 & 7126.0 & 7239.1 \\
2011 & 7637.3 & 7729.9 & 7806.7 & 7772.0 & 7523.2 \\
2012 & 8209.8 & 8255.1 & 8276.4 & 8185.3 & 7612.2 \\
2013 & 8979.1 & 8823.2 & 8806.5 & 8756.2 & 8706.5 \\
2014 & 9282.6 & 9315.8 & 9326.6 & 9207.8 & 8806.2 \\
2015 & 9457.3 & 9471.1 & 9401.3 & 9360.4 & 9493.6 \\
2016 & 9736.5 & 9699.7 & 9815.5 & 9682.7 & 9677.0 \\
2017 & 9642.7 & 9685.4 & 9722.9 & 9697.4 & 9581.4 \\
\hline
\end{tabular}


Table 2. Prediction of carbon emissions from agroforestry ecosystem in Provinces 2, 20102017

\begin{tabular}{c|c|c|c|c|c}
\hline Particular year & $\begin{array}{c}\text { Actual } \\
\text { emissions } \\
/ \mathbf{1 0}^{\mathbf{4}} \mathbf{t}\end{array}$ & $\begin{array}{c}\text { Paper } \\
\text { model } \\
/ \mathbf{1 0}^{\mathbf{4}} \mathbf{t}\end{array}$ & $\begin{array}{c}\text { Prediction model } \\
\text { based on tillage data } \\
\text { and meteorological } \\
\text { information } / \mathbf{1 0}^{\mathbf{4}} \mathbf{t}\end{array}$ & $\begin{array}{c}\text { Prediction model } \\
\text { based on least } \\
\text { square regression } \\
/ \mathbf{1 0}^{\mathbf{4}} \mathbf{t}\end{array}$ & $\begin{array}{c}\text { Forecasting } \\
\text { model based } \\
\text { on ridge } \\
\text { regression } \\
\text { method /10 }\end{array}$ \\
\hline 2010 & 6342.8 & 6315.4 & 6426.2 & 6259.9 & 6418.6 \\
2011 & 6675.4 & 6708.7 & 6759.8 & 6601.7 & 6724.3 \\
2012 & 6848.2 & 6872.2 & 6930.5 & 6779.2 & 6781.0 \\
2013 & 7350.5 & 7329.4 & 7287.6 & 7311.4 & 7393.8 \\
2014 & 7961.8 & 7969.3 & 7885.3 & 8006.2 & 7992.4 \\
2015 & 8400.6 & 8426.5 & 8492.3 & 8457.1 & 8351.5 \\
2016 & 8792.4 & 8817.8 & 8726.4 & 8869.5 & 8730.5 \\
2017 & 9033.0 & 9016.4 & 9106.6 & 9002.5 & 9084.3 \\
\hline
\end{tabular}

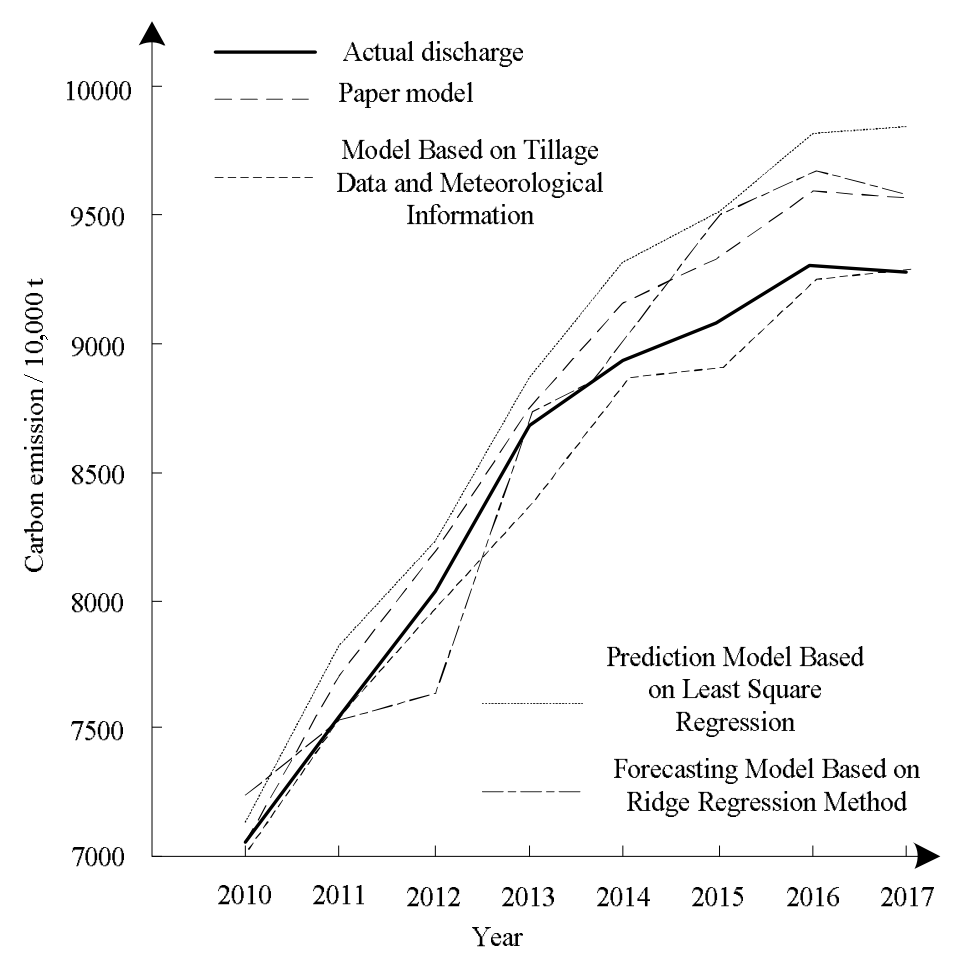

Figure 4. Prediction of carbon emissions from agroforestry ecosystem in Provinces 1, 20102017

Analysis Table 1 and Figure 4 show that the average carbon emissions of agroforestry ecosystem in the first province from 2010 to 2017 are about $8747.4 / 10^{4}$ t. The difference between the average carbon emissions predicted by this model and the average actual carbon emissions is the smallest, about $5.9 / 10^{4} \mathrm{t}$, while the differences between the other models and the actual emissions are $39.5 / 10^{4} \mathrm{t}, 23.9 / 10^{4} \mathrm{t}$ and $167.5 / 10^{4}$ t, respectively. Table 2 and Figure 5 show that the average carbon emissions 
of agroforestry ecosystems in the two provinces from 2010 to 2017 are about $7675.6 / 10^{4} \mathrm{t}$. The prediction results of this model are about $7682.0 / 10^{4} \mathrm{t}$ and the error is about $6.4 / 10^{4} \mathrm{t}$. The prediction results of the other three models are $7701.8 / 10^{4} \mathrm{t}$, $7660.9 / 10^{4} \mathrm{t}$ and $7684.6 / 10^{4} \mathrm{t}$, respectively. The prediction results of this model are the closest to the actual results. The experimental results show that the prediction accuracy of carbon emissions from agroforestry ecosystems is high.

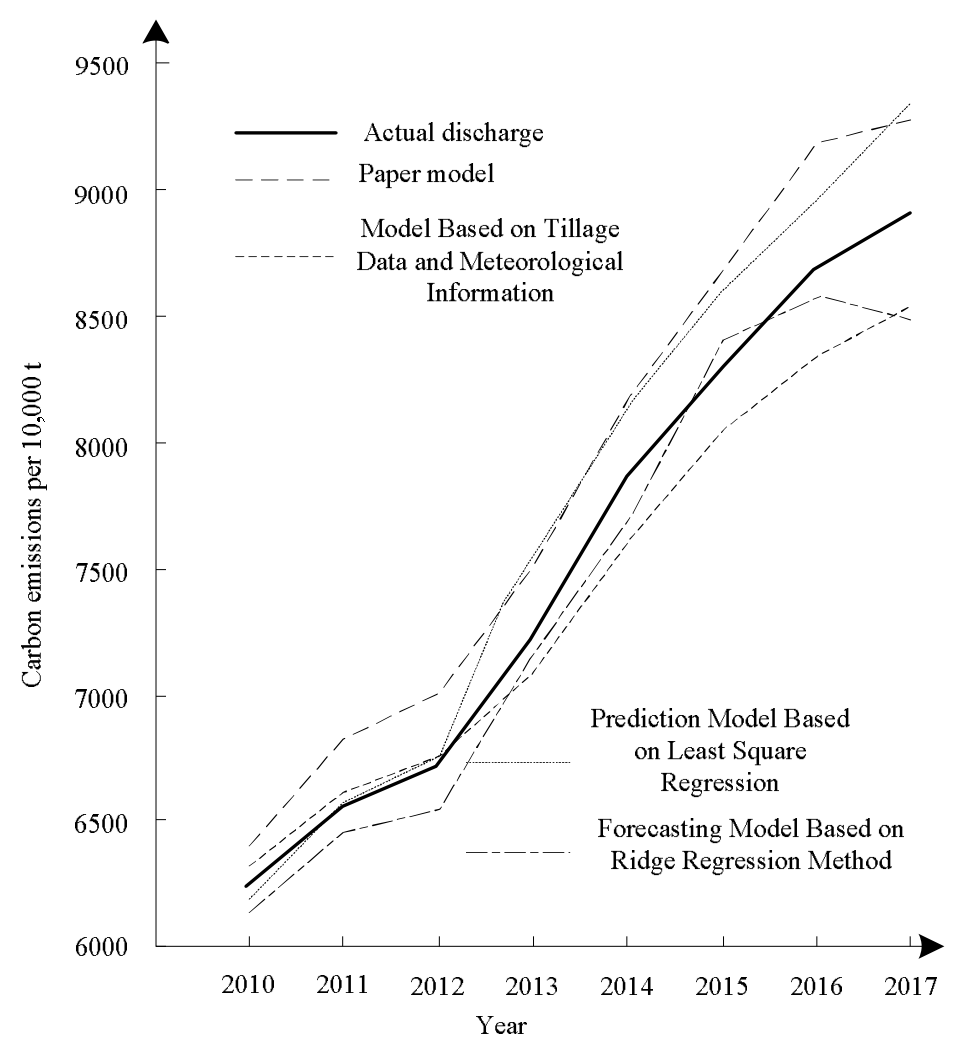

Figure 5. Prediction of carbon emissions from agroforestry ecosystem in Provinces 2, 2010 2017

\section{Analysis of correlation between of GDP and carbon emissions}

In order to analyze the correlation between GDP and carbon emissions of agroforestry ecosystem, the factors influencing carbon emissions in China in 2010, the factors predicted at different GDP growth rates and different agroforestry ecological consumption rates in 2011-2015 were normalized into the model, and the output results were inversely normalized. The predicted value of carbon emissions in China in 2010 was $1.026 \times 10^{7} \mathrm{t}$. The predicted carbon emissions during the 12th Five-Year Plan period at different GDP growth rates and different carbon emission ratios are shown in Table 3.

From the above analysis, the projected carbon emissions by 2030 can reach 10.49 billion tons. The model predicts that under the same GDP growth rate, the larger the proportion of agricultural and forestry ecological consumption decreases, the less carbon emissions, and the slower the growth of carbon emissions will be over time. This indicates that the optimization of agricultural and forestry ecological energy structure, 
especially the development and utilization of low-carbon energy, will be conducive to reducing the proportion of carbon dioxide in energy consumption, thereby slowing down the growth trend of carbon emissions. Under the same decline rate of ecological consumption of agriculture and forestry, the greater the growth rate of GDP, the more carbon emissions, and the faster the growth rate of carbon emissions over time, which shows that if we pursue the rapid growth of GDP too much, the carbon emissions in China will increase rapidly. Therefore, in the future, China can appropriately reduce the GDP growth target and continuously promote the optimization of energy structure to ensure the effective realization of carbon emission reduction targets.

Table 3. Carbon emission forecast value for 2011-2015 under different situations $\left(10^{4} \mathrm{t}\right)$

\begin{tabular}{c|c|c|c|c|c|c}
\hline $\begin{array}{c}\text { GDP growth } \\
\text { rate /\% }\end{array}$ & $\begin{array}{c}\text { The ratio of agricultural and } \\
\text { forestry ecological consumption } \\
\text { decreases /\% }\end{array}$ & In 2011 & In 2012 & In 2013 & In 2014 & In 2015 \\
\hline \multirow{3}{*}{7.0} & 0.80 & 8398 & 8765 & 9156 & 9573 & 10023 \\
& 1.12 & 8355 & 8680 & 9014 & 9389 & 9796 \\
7.5 & 1.40 & 8313 & 8595 & 8901 & 9233 & 9597 \\
& 0.80 & 8423 & 8831 & 9255 & 9748 & 10025 \\
8.0 & 1.12 & 8386 & 8742 & 9107 & 9544 & 10002 \\
& 1.40 & 8338 & 8668 & 8992 & 9371 & 9820 \\
& 0.80 & 8461 & 8893 & 9359 & 9890 & 10454 \\
8.5 & 1.12 & 8424 & 8822 & 9215 & 9682 & 10227 \\
& 1.40 & 8375 & 8730 & 9113 & 9547 & 10022 \\
& 0.80 & 8488 & 8963 & 9173 & 10063 & 10628 \\
9.0 & 1.12 & 8450 & 8891 & 9344 & 9878 & 10399 \\
& 1.40 & 8404 & 8800 & 9230 & $9696 \backslash$ & 10195 \\
& 0.80 & 8521 & 9034 & 9591 & 10187 & 10848 \\
& 1.12 & 8489 & 8950 & 9450 & 10036 & 10618 \\
\hline \multirow{2}{*}{8.40} & 8439 & 8861 & 9327 & 9868 & 10414 \\
\hline
\end{tabular}

\section{Analysis of model practicability}

In order to verify the practicability of the model, the model was used to predict soil carbon emissions under different vegetation cover in the agroforestry ecosystem of the experimental object 1 . Vegetation coverage refers to the ratio of the vertical projected area of plants to the area of a region, expressed as a percentage. The results are shown in Table 4.

Table 4 shows that the prediction errors are less than $9.80 / 10^{4} \mathrm{t}$ when the model is used to predict the soil carbon emissions under different vegetation cover in the agroforestry ecosystem. The experimental results show that the model can predict the soil carbon emissions in the agroforestry ecosystem comprehensively and has strong practicability.

\section{Analysis of model prediction efficiency}

In order to test the prediction efficiency of this model, the carbon emissions of agroforestry ecosystems in two provinces from 2006 to 2015 were predicted by using this model and the other three models respectively. The time required for different 
models to predict carbon emissions was compared. The results are shown in Tables 5 and 6 .

Analysis Tables 5 and 6 show that the time used to predict carbon emissions from agroforestry ecosystems in different years of the experimental object 1 is $3.64-4.53 \mathrm{~s}$, and the average time spent is $4.07 \mathrm{~s}$, while the average time spent by the other three systems is $7.39 \mathrm{~s}, 9.41 \mathrm{~s}$ and $8.20 \mathrm{~s}$ respectively. The model predicted the carbon emissions of agroforestry ecosystems in different years of the experimental subjects 2 in $3.85-4.69 \mathrm{~s}$, and the average time spent was $4.23 \mathrm{~s}$. The average time needed for the other three systems to predict carbon emissions was $7.65 \mathrm{~s}, 9.60 \mathrm{~s}$ and $8.55 \mathrm{~s}$, respectively. The experimental results show that it takes less time to predict the carbon emissions of agroforestry ecosystem by using the proposed model. The average time to predict the carbon emissions of different experimental objects is about $4.15 \mathrm{~s}$, which is the highest efficiency.

Table 4. Comparison of soil carbon emission rates under different vegetation covers in agroforestry ecosystem $\left(10^{4} t\right)$

\begin{tabular}{c|c|c|c}
\hline Vegetation & $\begin{array}{c}\text { Actual value of carbon } \\
\text { emissions }\end{array}$ & $\begin{array}{c}\text { Minimum predictive } \\
\text { value }\end{array}$ & Predicted maximum \\
\hline Degraded meadow & 256.2 & 253.66 & 261.69 \\
Degraded shrub & 350.81 & 346.52 & 354.95 \\
Kobresia meadow & 352.17 & 349.97 & 358.52 \\
Shrub meadow & 400.09 & 398.64 & 406.62 \\
Abandoned land & 612.25 & 607.08 & 616.19 \\
Young trees & 691.95 & 686.69 & 695.26 \\
Spring highland barley & 922.39 & 916.61 & 926.41 \\
Fir forest & 965.77 & 961.48 & 969.5 \\
Winter wheat & 1064.9 & 1060.25 & 1069.17 \\
Cutting slash & 1302.96 & 1298.72 & 1305.19 \\
\hline
\end{tabular}

Table 5. Time comparison of different models for predicting carbon emissions of experimental object 1

\begin{tabular}{c|c|c|c|c}
\hline Particular year & $\begin{array}{c}\text { Paper } \\
\text { model /s }\end{array}$ & $\begin{array}{c}\text { Prediction model based } \\
\text { on tillage data and } \\
\text { meteorological } \\
\text { information /s }\end{array}$ & $\begin{array}{c}\text { Prediction model } \\
\text { based on least square } \\
\text { regression /s }\end{array}$ & $\begin{array}{c}\text { Forecasting } \\
\text { model based on } \\
\text { ridge regression } \\
\text { method /s }\end{array}$ \\
\hline 2006 & 4.53 & 6.86 & 9.52 & 8.66 \\
2007 & 3.98 & 6.97 & 8.86 & 7.37 \\
2008 & 3.64 & 6.92 & 8.93 & 9.25 \\
2009 & 4.22 & 7.63 & 9.25 & 7.48 \\
2010 & 4.15 & 7.37 & 10.06 & 8.52 \\
2011 & 3.96 & 8.03 & 10.24 & 8.34 \\
2012 & 4.03 & 7.55 & 9.37 & 7.98 \\
2013 & 4.17 & 7.21 & 9.66 & 7.26 \\
2014 & 4.11 & 7.36 & 9.28 & 8.02 \\
2015 & 3.98 & 8.00 & 8.94 & 9.11 \\
\hline
\end{tabular}


Table 6. Time comparison of different models for predicting carbon emissions of experimental object 2

\begin{tabular}{l|c|c|c|c}
\hline Particular year & $\begin{array}{c}\text { Paper } \\
\text { model /s }\end{array}$ & $\begin{array}{c}\text { Prediction model based } \\
\text { on tillage data and } \\
\text { meteorological } \\
\text { information /s }\end{array}$ & $\begin{array}{c}\text { Prediction model } \\
\text { based on least square } \\
\text { regression /s }\end{array}$ & $\begin{array}{c}\text { Forecasting } \\
\text { model based on } \\
\text { ridge regression } \\
\text { method /s }\end{array}$ \\
\hline 2006 & 4.48 & 7.53 & 9.65 & 7.96 \\
2007 & 4.51 & 7.96 & 10.2 & 8.05 \\
2008 & 4.69 & 8.11 & 9.37 & 8.44 \\
2009 & 3.98 & 8.27 & 9.51 & 8.93 \\
2010 & 3.96 & 7.54 & 8.83 & 7.99 \\
2011 & 4.22 & 6.68 & 9.42 & 8.42 \\
2012 & 4.16 & 7.92 & 10.06 & 9.38 \\
2013 & 4.37 & 8.05 & 8.9 & 8.76 \\
2014 & 3.85 & 7.44 & 9.92 & 8.35 \\
2015 & 4.03 & 6.99 & 10.11 & 9.24 \\
\hline
\end{tabular}

\section{Discussion}

This paper puts forward policy suggestions on carbon emission reduction in agroforestry ecosystem from four aspects: developing agroforestry ecosystem economy, improving agroforestry ecosystem efficiency, adjusting agroforestry ecosystem structure and scientific management. China ranks first among the world's largest carbon emitters, the United States second, and India third, according to data. According to a 2016 report by the American Lung Association, more than half of people in the United States face the risk of breathing air pollution, with carbon dioxide emissions of 54.14 million tons. Although India has signed agreements to reduce emissions and use clean energy, 1.2 million people die every year from respiratory diseases (Deo et al., 2016; Tian and Wang, 2016; Xiao et al., 2018).

\section{Improving the development level of agroforestry ecosystem and vigorously developing low-carbon agroforestry ecosystem}

Carbon emissions of agroforestry ecosystems in China are increasing year by year, and the level of economic development of agroforestry ecosystems plays the most important role in promoting the scale of carbon emissions of agroforestry ecosystems expands with the rapid development of agroforestry ecosystems. But the hard measures to restrain economic growth are not advisable. The key is to improve the quality of economic development of agroforestry ecosystem. As long as agroforestry ecosystem takes the road of sustainable development, we can get economic growth and environmental quality improvement at the same time (Brahma et al., 2018; Norhayati Rashid, 2017).

First of all, it needs to be supported by a good policy and legal environment, a perfect training system for new farmers and practical talents, a modern agroforestry ecosystem production and management system, and diversified farmers' cooperative organizations. It exploratively brings the emission reduction of agroforestry ecosystem into the track of legalization, so that the emission reduction of agroforestry ecosystem can be legalized. Secondly, we should increase investment in the development of low-carbon agroforestry 
ecosystems. It will increase investment in agroforestry ecosystem infrastructure and vigorously develop core technologies in the field of low-carbon agroforestry ecosystem.

\section{Improving the productivity of agroforestry ecosystem and reducing the carbon emission intensity of agroforestry ecosystem}

The improvement of production efficiency of agroforestry ecosystem plays a positive role in reducing carbon emission of agroforestry ecosystem. Although the intensity of carbon emission of agroforestry ecosystem in China is decreasing year by year, the production efficiency of agroforestry ecosystem in China is still low. Improving the productivity of agroforestry ecosystem does not only mean scale and mechanization. For example, the scale and mechanization model of the United States brings about high land productivity and commodity efficiency, but also high pollution and high consumption. Therefore, our efficient agroforestry ecosystem should be a technological route with biochemical technology as the main and mechanical technology, promoting the research and development and application of scientific research and innovation, and improving the utilization efficiency of various agricultural funds.

In order to achieve a reasonable combination of nitrogen, phosphorus and potassium fertilizers, it is necessary to apply fertilizers strategically according to different soil nutrient conditions, so as to reduce carbon emissions in the production and transportation of chemical fertilizers, as well as direct carbon emissions in the application process. Promoting the comprehensive utilization of straw resources, strengthening recycling and returning straw to the field will help to improve the soil nutrient status, increase organic matter and improve the soil fertility level (Saleh et al., 2016). Straw can be silage, ammoniation, compaction, microbial fermentation and other ways to produce breeding feed, effectively improve the utilization efficiency of straw resources; biological insecticide-repellent method is used to replace pesticides, using the medicinal properties of various plants in nature and the intergrowth of organisms to achieve the method of resisting pests.

\section{Adjusting the industrial structure of agroforestry ecosystem and reducing the carbon emission of agroforestry ecosystem}

The adjustment of industrial structure of agroforestry ecosystem is helpful to reduce carbon emission of agroforestry ecosystem. On the basis of ensuring basic food security, regions should base themselves on resource advantages, face market demand, and develop their own advantages and characteristic departments according to their own resource enjoyment.

First, we should increase the gross domestic product of forestry, fishery and animal husbandry, change the traditional agroforestry ecosystem model and develop diversified agroforestry ecosystems. For example, the emerging agroforestry ecosystem, which combines the traditional agroforestry ecosystem with tourism, meets the requirements of the development of ecological economy, and improves the comprehensive capacity of agroforestry ecosystem production by promoting the comprehensive development of various sectors of agriculture, forestry, animal husbandry and fishery. In the process of structural adjustment of agroforestry ecosystem, each subject should be clearly positioned to give full play to their respective effects. Secondly, we should combine the actual situation, find out the advantages and breakthroughs, scientifically and rationally adjust the structure of planting industry, and combine with aquaculture. Under the condition of 
guaranteeing the supply of basic grain, efforts should be made to develop the planting industries of peanut, cotton, rape and other cash crops, such as building dry and fresh fruit bases, expanding industrial and vegetable bases, and vigorously planting characteristic horticultural crops.

\section{Implementing scientific farmland management technology}

The dynamic change of organic carbon in agroforestry ecosystem is not only affected by natural factors such as temperature, precipitation and vegetation types, but also by agricultural management measures such as fertilization, straw returning, no-tillage and irrigation. Under the current planting mode, the space for increasing the carbon sequestration effect of agroforestry ecosystem through the improvement of existing management measures has been very small, and the potential for further carbon sequestration is limited. In order to further improve the carbon sequestration capacity of agroforestry ecosystem, we must implement scientific agroforestry ecosystem management technology, reduce the carbon dioxide emissions from the residual root decomposition after harvesting, and further improve the carbon sequestration capacity to the residual root decomposition after harvesting, such as scientific irrigation, rational fertilization and so on.

\section{Conclusions}

In this paper, a prediction model of carbon emissions in agroforestry ecosystem based on support vector regression machine is designed. Seven different kinds of carbon sources in root system are selected as influencing factors of carbon emissions in agroforestry ecosystem. According to the basic principle of support vector regression machine, a prediction model of carbon emissions in agroforestry ecosystem is established. The prediction model predicts carbon emissions in agroforestry ecosystem based on seven influencing factors data. Experiments show that the difference between the average carbon emission and the actual average carbon emission of agricultural and forestry ecosystems in the two provinces are 5.9/10 $\mathrm{t}$ and $6.4 / 10^{4} \mathrm{t}$ respectively, which is lower than that of other prediction models. The prediction model predicts that under the same GDP growth rate, the optimization of the energy structure of agricultural and forestry ecosystems is conducive to reducing the proportion of carbon dioxide in energy consumption, thus reducing the proportion of carbon dioxide in energy consumption. The average time used to predict the carbon emissions of agricultural and forestry ecosystems in different years was $4.07 \mathrm{~s}$ and $4.23 \mathrm{~s}$, respectively, which was lower than the average time of other prediction models. The experimental results showed that the model in this paper can predict carbon emissions of agroforestry ecosystem quickly and completely.

Acknowledgements. The article takes study cases in Anhui province of China.

\section{REFERENCES}

[1] Anderegg, W., Schwalm, C., Biondi, F. (2015): Forest ecology. Pervasive drought legacies in forest ecosystems and their implications for carbon cycle models. - Science 349(6247): 528-32. 
[2] Babaranti, O., Horn, S., Jowett, T., Frew, R. (2019): Isotopic signatures in Mytilus galloprovincialisand Ulva latuca as bioindicators for assessing discharged sewage effluent in coastal waters along Otago Peninsula, New Zealand. - Geology, Ecology, and Landscapes 3(1): 53-64. DOI: 10.1080/24749508.2018.1485079.

[3] Benjamin, E., Ola, O., Buchenrieder, G. (2018): Does an agroforestry scheme with payment for ecosystem services (PES) economically empower women in sub-Saharan Africa? - Ecosystem Services 31(A): 1-11.

[4] Brahma, B., Pathak, K., Lal, R. et al. (2018): Ecosystem carbon sequestration through restoration of degraded lands in Northeast India. - Land Degradation \& Development 29(1): 41-64.

[5] Brogniez, D., Ballabio, C., Stevens, A. (2015): A map of the topsoil organic carbon content of Europe generated by a generalized additive model. - European Journal of Soil Science 66(1): 121-134.

[6] Carsan, S., Stroebel, A., Dawson, I. (2015): Can agroforestry option values improve the functioning of drivers of agricultural intensification in Africa? - Annals of Physics 99(2): 434-458.

[7] Deo, R. C., Samui, P., Kim, D. (2016): Estimation of monthly evaporative loss using relevance vector machine, extreme learning machine and multivariate adaptive regression spline models. - Stochastic Environmental Research \& Risk Assessment 30(6): 17691784.

[8] Dressler, W., Wilson, D., Clendenning, J. (2015): Examining how long fallow swidden systems impact upon livelihood and ecosystem services outcomes compared with alternative land-uses in the uplands of Southeast Asia. - Journal of Development Effectiveness 7(2): 210-229.

[9] Franzluebbers, A., Chappell, J., Wei, S. (2016): Greenhouse gas emissions in an agroforestry system of the southeastern USA. - Nutrient Cycling in Agroecosystems 10(1): 1-16.

[10] Grinblat, G., Uzal, L., Verdes, P. (2015): Nonstationary regression with support vector machines. - Neural Computing \& Applications 26(3): 641-649.

[11] He, J., Rong, L. (2015): Limits of state-led programs of payment for ecosystem services: field evidence from the sloping land conversion program in Southwest China. - Human Ecology 43(5): 1-10.

[12] Helen, K. (2016): Commodification of natural resources and forest ecosystem services: examining implications for forest protection. - Environmental Conservation 44(1): 24-33.

[13] Khanchoul, K., Boubehziz, S. (2019): Spatial variability of soil erodibility at El Hammam catchment, Northeast of Algeria. - Environment \& Ecosystem Science 3(1): 17-25.

[14] Khanchoul, K., Boukhrissa, Z. A. (2019): Assessing suspended sediment yield in the Saf Saf Gauged catchment, Northeastern Algeria. - Malaysian Journal of Geosciences 3(2): 07-11.

[15] Maas, B., Tscharntke, T., Saleh, S. (2015): Avian species identity drives predation success in tropical cacao agroforestry. - Journal of Applied Ecology 52(3): 735-743.

[16] Marilice, C., Mendonça, S., Horokoski, T. (2015): Carbon sequestration and riparian zones: assessing the impacts of changing regulatory practices in Southern Brazil. - Land Use Policy 42(42): 329-339.

[17] Michael, A., Terry, R., Eric, D., Zakiya, L., Eric, B. (2015): Loblolly pine age and density affects switchgrass growth and soil carbon in an agroforestry system. - Forest Science 58(5): 485-496.

[18] Norhayati, I., Rashid, M. (2017): Adaptive neuro-fuzzy prediction of carbon monoxide emission from a clinical waste incineration plant. - Neural Computing \& Applications 2017: 1-13.

[19] Ogunkunle, T. J., Adewumi, A. A., Adeyinka, O. (2019): Biodiversity: overexploited but underutilized natural resource for human existence and economic development. Environment \& Ecosystem Science 3(1): 26-34. 
[20] Onwuka, O. S., Ezugwu, C. K., Ifediegwu, S. I. (2019): Assessment of the impact of onsite sanitary sewage system and agricultural wastes on groundwater quality in Ikem and its environs, south-eastern Nigeria. - Geology, Ecology, and Landscapes 3(1): 65-81. DOI: $10.1080 / 24749508.2018 .1493635$.

[21] Ouyang, H., Liu, Z., Wang, L., Peng, W., Deng, H., Ashraf, M. A. (2018): Fungicidal activity and bamboo preservation of Pinus elliottii needles extracts. - Wood Research 63(4): 533-546.

[22] Oyedotun, T. D. T., Johnson-Bhola, L. (2019): Beach litter and grading of the coastal landscape for tourism development in sections of Guyana's coast. - Journal Clean WAS 3(1): 01-09.

[23] Ping, Z., Liang, H., Xin, F. (2015): Ecosystem service value assessment and contribution factor analysis of land use change in Miyun County, China. - Sustainability 7(6): 73337356.

[24] Roslee, R. (2019): Engineering Geological investigation on Karambunai-Lok Bunuq landslides, Kota Kinabalu, Sabah. - Malaysian Journal of Geosciences 3(2): 01-06.

[25] Rueda, X., Thomas, N., Lambin, E. (2015): Eco-certification and coffee cultivation enhance tree cover and forest connectivity in the Colombian coffee landscapes. Regional Environmental Change 15(1): 25-33.

[26] Saleh, C., Dzakiyullah, N. R., Nugroho, J. B. (2016): Carbon dioxide emission prediction using support vector machine. - IOP Conference Series: Materials Science and Engineering 114(1): 012148.

[27] Sharma, S., Upadhyay, S., Singh, B. (2019): Employment opportunities with promoting waste management in India. - Journal Clean Was 3(1): 10-15.

[28] Sinare, H., Gordon, L. (2015): Ecosystem services from woody vegetation on agricultural lands in Sudano-Sahelian West Africa. - Agriculture Ecosystems \& Environment 200(200): 186-199.

[29] Sloat, L. L., Henderson, A., Lamanna, C. (2015): The effect of the foresummer drought on carbon exchange in Subalpine meadows. - Ecosystems 18(3): 533-545.

[30] Terrado, M., Tauler, R., Bennett, E. (2015): Landscape and local factors influence water purification in the Monteregian agroecosystem in Québec, Canada. - Regional Environmental Change 15(8): 1743-1755.

[31] Tian, Y., Xu, Y. P., Wang, G. (2018): Agricultural drought prediction using climate indices based on support vector regression in Xiangjiang River basin. - Science of the Total Environment 622-623: 710-720.

[32] Vignola, R., Harvey, C., Bautista-Solis, P. (2015): Ecosystem-based adaptation for smallholder farmers: Definitions, opportunities and constraints. - Agriculture Ecosystems \& Environment 211(211): 126-132.

[33] Wall, G., Garcia, R., Kimball, B. (2015): Interactive effects of elevated carbon dioxide and drought on wheat. - Agronomy Journal 98(2): 354-381.

[34] Xiao, X., Zhang, T., Zhong, X. et al. (2018): Support vector regression snow-depth retrieval algorithm using passive microwave remote sensing data. - Remote Sensing of Environment 210: 48-64.

[35] Zhang, Y., Xiao, Q., Huang, M. (2016): Temporal stability analysis identifies soil water relations under different land use types in an oasis agroforestry ecosystem. - Geoderma 271: $150-160$. 